\title{
Pressure-Volume Relationship and Fluid Content in Fetal Rabbit Lung after $\boldsymbol{\beta}$-Receptor-Stimulating Drugs
}

\author{
B. BERGMAN, T. IIEDNER, AND) P. LUNDBOR(; \\ Departments of Ohstetrics and (ivnecology and Pharmacologt. University of Ciotehorg. Ciotehorg. Sweden
}

\begin{abstract}
Summary
A considerable interest has been focused on the effects of various drugs on fetal and neonatal pulmonary maturation and adaptation. In the present study, we have investigated the effects of the selective $\beta_{1}$ - and $\beta_{2}$-receptor-stimulating agents prenalterol and terbutaline on the pressure-volume relationship and fluid content in fetal rabbit lung at 28 days of gestation. Pressurevolume recordings during deflation showed significantly increased lung volumes at equivalent transpulmonary pressures in terbutaline-treated fetuses as compared to controls. No such effect was noted after prenalterol. In the control animals, wet lung weight/ body weight ratio decreased to a steady state level $60 \mathrm{~min}$ after birth, indicating a rapid dehydration of the lungs. This dehydration was present at delivery after terbutaline and prenalterol treatment. The amount of fluid collected from the airways was also reduced after terbutaline and prenalterol treatment. The present results indicate facilitated neonat al respiratory adaptation after especially terbutaline treatment. Possible mechanisms behind these effects are discussed.
\end{abstract}

From studies on the pharmacologic action of sympathomimetic agents, Lands et al. (20) postulated the presence of two distinct types of $\beta$-receptors. $\beta_{1}$ and $\beta_{2}$. Either of these receptors was considered to be present in different organs. e.g. the $\beta_{1}$-type in the heart and the $\beta$-type in the bronchioles and uterus. However. more recent studies $(9.10)$ have demonstrated that both types of receptors are present in the heart and lung tissue. In accordance with these findings, the net effect after $\beta$-receptor stimulation depends on the local relationship between the two types of receptors. The presence of $\beta$-receptors in the fetus has been demonstrated in various species at an early gestational age (22).

Antenatal corticosteroid treatment is for the time being the usual therapeutic regimen for acceleration of fetal lung maturation. However, there is now both clinical and experimental evidence that lung adaptation in the preterm neonate can be enhanced by alternative pharmacologic methods, such as $\beta$-mimetic agents $(3,5,7,16)$. Studies on the fetal rabbit lung using inflationdethation recerdings have shown that the deflation curve correlates particularly well with other parameters as an indicator of lung distensibility. Wyszogrodski et al. (25) have shown that administration of the relatively unselective $\beta$-mimetic, isoxuprine, causes enhanced retention of air in the rabbit lung during the deflation phase.

The aim of the present investigation was to study the effects of

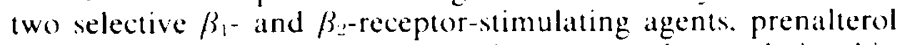
and terbutaline. on fluid content and pressure-volume relationship in the fetal rabbit lung, with particular emphasis on the deflation phase of the recordings.

\section{MATHRIALS AND MLTHOOS}

Twenty-six white and black rabbits of Danish rural breed were mated with two bucks under direcl observation. Copulation was considered as zero time of gestation. The does were kept in separate cages in the department and fed on standard pellets and water ad libitum. Three days before term, at 28 days of gestation. the does were anesthetized with ether administered by open mask. The uterus was exposed by a midline abdominal incision. Terbutaline $(0.1 \mathrm{mg}$ in $0.1 \mathrm{ml}$ normal saline). prenalterol (0). $\mathrm{mg}$ in 0.1 $\mathrm{ml}$ normal saline), or normal saline were alternatively injected IM into the fetuses through the intact uterine wall. The abdominal incision was closed with a continuous suture. and the does were allowed to recover. After $3 \mathrm{hr}$. the abdomen was reopened. and the fetal rabbits were delivered by hysterotomy.

The fetuses used in the pressure-volume measurements and those used for fetal pulmonary fluid (FPF) collection were allowed to remain within the amniotic sac to prevent air breathing, whereas the other fetuses were removed and allowed to breathe for periods ranging from 15 to $120 \mathrm{~min}$.

After weighing the newborn carcass, the trachea was exposed. and a polyethylene tubing (Portex pp 90) was inserted. The tube was attached through a $\mathrm{Y}$-connection to a narrow-bore $(3 \mathrm{~mm})$ water manometer and a calibrated gas-tight syringe containing 5.0 $\mathrm{ml}$ of air. The FPF was evacuated by applying a negative pressure of $5 \mathrm{~cm} \mathrm{H}$ O for $5 \mathrm{~min}$. The tube including FPF. both with known weight per $\mathrm{cm}$, was then removed and weighed or left in situ and measured. Before the pressure-volume recordings were performed. the FPF was restored into the bronchial tree by increasing the pressure to $0 \mathrm{~cm} \mathrm{H.O}$. The lungs were inflated and deflated with air in pressure steps of $5 \mathrm{~cm} \mathrm{H.O}$. and the volume readings of the syringe were made after 2 min of equilibration at each pressure interval. Correction was made for the volume displaced into the manometer and for the compression of air. The volume of air in the lungs at $35 \mathrm{~cm} \mathrm{H} \mathrm{H}_{2}$ was defined as total lung capacity (TLC) The occasional presence of a pneumothorax was indicated by failure of equilibrium at maximal inflation and conlirmed hy opening the abdominal cavity to inspect the diaphragms. Recordings were performed in all animals within $3 \mathrm{hr}$ after death. an interval reported not to change the pressure-volume curves ( 18 ).

In all animals, the thorax was opened. and the lungs were extracted and weighed. The lungs were desiccated by exposure to $1000^{\circ} \mathrm{C}$ in a drying oven for $24 \mathrm{hr}$ and reweighed to obtain dry lung weight. The ratio of wet lung weight (WLW) to body weight (BW) was calculated from the measurements of $B W$ and WLW including $\mathrm{FPF}$.

Several of the animals not allowed to breathe were used for all measurements (pressure-volume. FPI and WLW/BW). However. for technical reasons such as preparation errors, animals left more than $3 \mathrm{hr}$ after death. and pneumothorax, some fetuses were used for only one or two of these procedures.

In the statistical analysis of all data. Student's $t$ test was used.

\section{RLSUITS}

The study included 73 controls. 81 terbutaline, and 53 prenalterol-treated animals (Table 1). No differences were noted in mean body weight or dry lung weight between the different groups. 


\section{PRESSURE-VOLUME RECORDING iS}

The pressure-volume curves at 28 days of gestation expressed as percentage of TLC and as $\mathrm{ml}$ air per $100 \mathrm{mg}$ dry lung weight are shown in Figures $I$ and 2.

The different transpulmonary pressure levels expressed as a percentage of TLC did not differ between the control, terbutaline, or prenalterol groups during inflation. At deflation, a significantly higher volume of air was retained in the lungs of the terbutalinetreated fetuses compared to the controls. At low-pressure intervals,

Table 1. Details of material

\begin{tabular}{lccc}
\multicolumn{1}{c}{ Treatment } & $\begin{array}{c}\text { No. of } \\
\text { fetuses }\end{array}$ & BW $(\mathrm{g})$ & $\begin{array}{c}\text { Dry lung wt } \\
(\mathrm{mg})\end{array}$ \\
\hline Terbutaline & 81 & $35.5 \pm 0.7^{2} \mathrm{NS}$ & $116.5 \pm 3.1 \mathrm{NS}$ \\
Prenalteral & 53 & $34.8 \pm 0.7 \mathrm{NS}$ & $118.5 \pm 3.5 \mathrm{NS}$ \\
Control & 73 & $35.3 \pm 1.1$ & $111.9 \pm 3.9$ \\
\hline
\end{tabular}

' Number of litters $=26$.

${ }^{2}$ Mean \pm S.E the difference was approximately $10 \%$. No such difference was noted between the prenalterol and the control animals during deflation (Fig. 1).

When the pressure-volume recordings were expressed as $\mathrm{ml}$ air per $100 \mathrm{mg}$ dry lung weight. although the differences were not significant. the TLC in the terbutaline group tended to increase compared to the control group. but the opposite tendency was noted in the prenalterol-treated animals. The pressure-volume curves of the fetuses given injections of terbutaline $3 \mathrm{hr}$ before delivery showed greater retention of air $(\mathrm{ml} / 100 \mathrm{mg}$ dry lung weight) both at inflation and deflation compared to controls. In the prenalterol-treated group, the inflation curve did not differ from the control recordings, but at deflation, a significantly lower lung volume was noted at 5 and $15 \mathrm{~cm} \mathrm{H}_{2} \mathrm{O}$.

\section{PUIMONARY FI.UID CONTENT}

The fluid content in the lungs, expressed as $\mathrm{WLW} / \mathrm{BW} \times 1000$, decreased rapidly after birth in the control animals. During the first $60 \mathrm{~min}$ after birth. WLW $/ \mathrm{BW} \times 1000$ decreased approximately $25 \%$ to a steady state level $(0 \mathrm{~min}$ versus 60 or $120 \mathrm{~min}: P$ $<0.001)$. The lungs of the terbutaline-treated fetuses were at the same steady state level as those of the control animals already at the time of birth. This phenomenon, although not so pronounced. was also noted in the fetuses which had received prenalterol $3 \mathrm{hr}$ before birth (Fig. 3).

The amount of fluid collected from the bronchioalveolar space at birth from the controls, the terbutaline-, or prenalterol-treated fetuses is shown in Figure 4. A 65\% reduction of FPF was noted after terbutaline treatment as compared to controls. In the fetuses given prenalterol $3 \mathrm{hr}$ before birth. FPF was reduced by approximately $50 \%$.

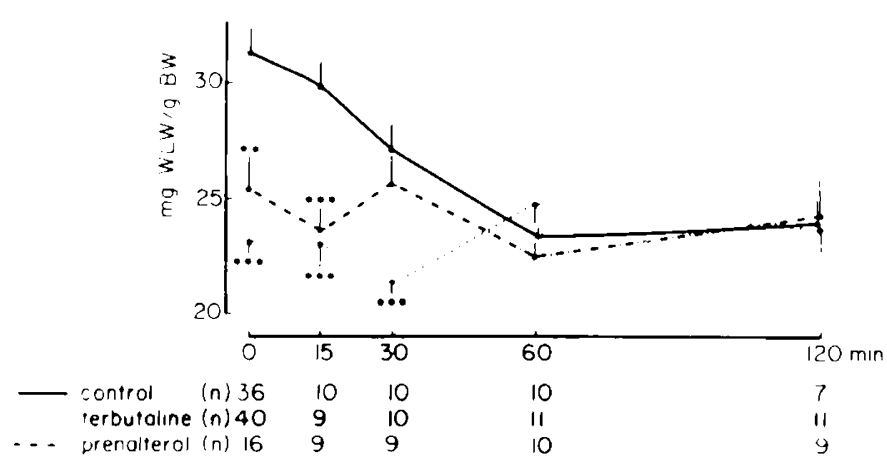

Fig. 3. Lung fluid content during the first 2 hr after birth expressed as $\mathrm{mg} W \mathrm{WW}$ perg BW. Mean $\pm \mathrm{S} . \mathrm{E} .{ }^{* *} . P<0.01 .{ }^{* * *}, P<0.0(0) 1$

\section{FETAL PULMONARY FLUID}

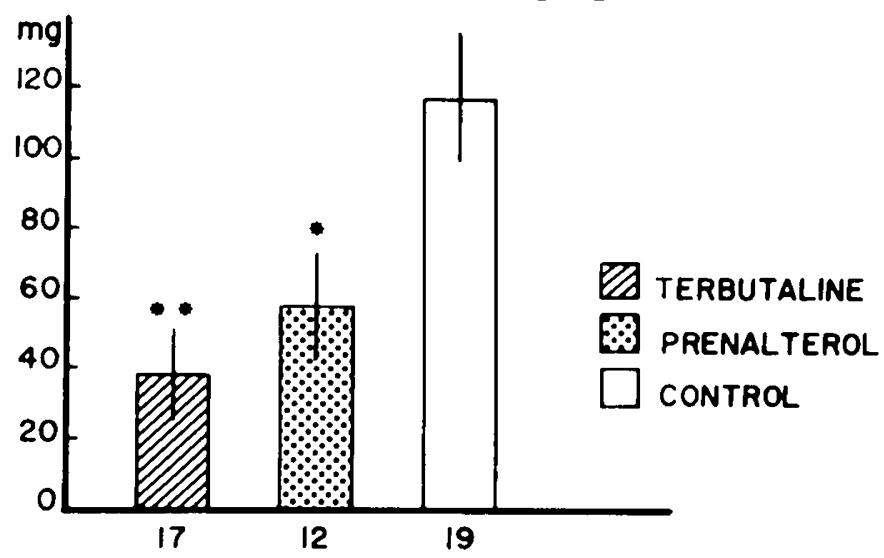

Fig. 4. Fetal pulmonary tluid collected from the hronchioalveolar space at birth. Mean \pm S.I. Numerals, number of experiments. ${ }^{*} . P<0.05: * *$ $P<0.01$. 


\section{DISC USSION}

The relationship between $\beta_{1}$ - and $\beta_{2}$-receptors in the organism varies between different organs and different individuals (13). The dominating $\beta$-receptor type in the lungs is of the $\beta$-type $(9,20)$. In the present study, the terbutaline-treated animals had an increased TLC compared to the prenalterol group. A tentative explanation to this finding might be the $\beta$--mediated dilatation of the bronchioles. The group of animals treated with prenalterol tended to decrease in TLC compared to the controls which might be explained by the evidence that this substance seems to have a weak $\beta$. antagonistic effect ( 8 ). Thus prenalterol might antagonize the surfactant-releasing and bronchodilating effect of endogenously secreted catecholamines which occurs at birth (19).

The volume of air present in the lung at low transpulmonary pressures has been shown to correlate well with other parameters of measuring alveolar surface active material (11). The percentage of air retained in the fetal lungs at low transpulmonary pressures at deflation after terbutaline treatment was significantly increased compared to the controls. No such effect was present after prenalterol administration. This finding is indicative of increased presence of surface active material in the fetal lungs after $\beta_{2}$ adrenoceptor stimulation. In fact, in a previous study, we have actually found an increased amount of lecithin in alveolar lavage of 28-day-old fetuses whose mothers had received terbutaline (5). Similarly, other authors have found an increased $\mathrm{L} / \mathrm{S}$ ratio in alveolar lavage fluid in 28 -day-old rabbit fetuses treated with unselective $\beta$-mimetics, such as isoxuprine $(12,15)$. The mechanism behind the increased amounts of surfactant phospholipids on the alveolar lining in the 28-day-old fetal rabbit lung is probably due to an enhanced release and possibly also to an enhanced synthesis of surfactants, which might be caused by the $\beta$-adrenergic-mediated increase in intracellular content of cyclic adenosine $3^{\prime}: 5^{\prime}$-monophosphate (2). The corticosteroid receptors. which appear in the rabbit fetal lungs around day 20 of gestation and increase in number to reach a maximum by day 28 , do not increase in number after treatment with $\beta$-mimetic agents. The plasma levels of corticosteroids in rabbit fetuses are also unaffected by $\beta$-receptor-stimulating agents (6). In the study of Bichler et al. (6), $\beta$-receptor-stimulating agents had no effect on the dipalmitoyllecithin levels in alveolar lavage or lung homogenate of fetal rabbits. However, this study was performed on the 25 th and 30 th days of gestation. The lack of effects is not surprising because on the 25 th day of gestation the rabbit fetal lung is not yet morphologically mature. and on the 30 th day of gestation. biochemical maturation is already completed. Thus, the effect of $\beta$-mimetics to increase the release and possibly also the synthesis of surfactants seem to be limited to some few days of gestation. In the rabbit fetus, $\beta$-receptor-stimulating agents seem to be effective around the 28 th day of gestation. when the lung is morphologically but not biochemically mature (14, 17). This statement is further supported by the findings of Wyszogrodski et al. (25) who showed an improved pulmonary adaptation as measured by pressure-volume characteristics after isoxuprine in 28 -day-old, but not in 26 or 27 day-old rabbit fetuses. On the 29 th day of gestation, the biochemical maturation seems to be completed. and further increase in lung distensibility cannot be achieved (17)

In the rabbit fetus, there is a decrease in the WLW/BW ratio during the first $2 \mathrm{hr}$ after birth, indicating a dehydration of the lungs. Previous studies have shown that adrenergic agonists, such as adrenaline. isoprenaline, and isoxuprine, cause a dehydration of the fetal lung $(1,12,24)$. In the present study, we can demonstrate that both $\beta_{1}$ - and $\beta_{2}$-receptor-stimulating agents can reduce the WLW/BW ratio and the amount of FPF at the time of birth. $A$ reduced $W L W / B W$ ratio after terbutaline and prenalterol was noted as early as 15 to $30 \mathrm{~min}$ of postnatal life. After $60 \mathrm{~min}$. when the control animals had reached a steady state level. no further differences were noted between the prenalterol- or terbutaline-treated and control animals. Moreover, there is evidence that endogenous catecholamines, and thus $\beta$-stimulation, are very high in the blood during labor and at the time of birth (19). By giving $\beta$-mimetics prenatally, we might therefore mimic the increased activity of the adrenal medulla which occurs at birth and thus precede the beneficial effect on the postnatal pulmonary adaptation by naturally occurring catecholamines.

The exact mechanism behind this $\beta$-mimetic-mediated response is not fully known. Several tentative explanations are possible. such as changes in pulmonary hemodynamics, direct effects on the respiratory epithelium responsible for secretion of lung liquid, or effects on the postcapillary venular leakage of fluid (12.21, 23, 24). However, earlier studies by Olver and Strang (21) indicate that changes in fetal pulmonary blood pressure do not influence the rate of production of FPF, and therefore, it seems more likely that $\beta$-mimetics have a direct effect on the production of FPF by the respiratory epithelium or disappearance of fluid by the postcapillary venular leakage sites.

In summary, the present study demonstrates that both $\beta_{1}$ - and $\beta$-receptor-stimulating agents enhance the pulmonary dehydration in the immediate postnatal period. The $\beta$--receptor agonist. terbutaline, also caused an increased pulmonary distensibility, which might be beneficial in early postnatal pulmonary adaptation.

\section{RFHERENCIS AND NOTES}

1. Aherne, W., and Dawkins. M. J. R.: The renoval of tluid from the pulmonary airways after bisth in the rabbit and the effect on this of prematurity and prenatal hypoxia. Biol. Neonat.. 7214 (1964).

2. Barrett. (. T.. Sevanian. A. Lavin. N.. and Kaplan. S. A.: Role of adenosine $3^{\prime} 5^{\prime}$-monophosphate in maturation of fetal lungs. Pediatr. Res.. N): 621 (1976)

3. Bergman. B.. and Hedner, T.: Antepartum administration of terbutaline and the incidence of hyaline membrane disease in preterm infants. Acta Obstet. (iynecol. Scand. 57: $217(1978)$.

4. Bergman. B.. Hedner. T.. and l.undborg. P.: Effect of terbutaline on the pressure volume relationship in fetal rabbit lung. Acta Obstet. (iynecol. Scand.. $5 ?: 323$ (1) $197 x$.

5. Bergman. B.. Hedner. T., and Lundborg. P.: Effect of terbutaline on lecthin content in alveolar lung wash in tetal rabbits. Acta Physiol. Scand.. 105: 378 (1979).

6. Bichler. A. Wiesinger. $M$, and Mayr, P.: Untersuchungen uber Iffekt und Wirkungsmechanismus des Beta-Sympathomimeticums Ritodrine aut Synthese und Fresetzung von Dipalmitoyl-lecithin in der fetalen Kaninchenlunge. Arch. (iynecol.. 2:- 29 (1979).

7. Bogg. (i. Ben Brahim, M.. and (iandar. R.: Beta-mmetic drugs and possible prevention of respiratory distress syndrome. $\mathrm{Br}$. J. Obstet. (ivnaecol.. \&2: $2 \times 5$ (1975).

x. Carlson. E.: (personal communication).

9. Carlsoon. F. Ablad. B.. Brandstrom, A. and (arlsson. B.: Differentiated blockade of the chronotropic effects of various adrenergic stimuli in the cat heart. life Sci.. /1: $453(1972)$.

10. Carkson. E.. Dahlot, ( C. (i. Hedherg. A.. Persion. H.. and Tangstrand. B.: Differentiation of cardac chronotropic and inotropic effects of heta-adrenoceptor agonists. Naunyn-Schmiedeberg's Arch. Pharmacol.. 306: 101 (1977)

11. Clements, J. A. Hustead, R. F.. Johnson, R. P.. and Bribets, I.: Pulmonary surface tension and alveolar stability. J. Appl. Physiol., /6: 444 (1961)

12. Vinhorning. (i.. ('hamberlain. D.. Contreras, (;.. Burgoyne. R., and Robertsson B.: Isoxuprine-induced release of pulmonary surfactant in the rabbit fetus. Am. J. Obstet Ginecol. 129: 197 (1977).

13. Furchgott, R. F.: Postsynaptic adrenergic receptor mechanisms in vascular smooth muscle. In: J. A. Bevan et al: Vascular Neuroeffector Mechanisms Second International Symposium. Odense 1975, p. 131 (Karger. Basel. 1976).

14. Gluck, L.. Sribney. M. and Kulovich. M. V.: The biochemical development of surface activity in mamnalian lung. 11. The biosynthesis of phospholipids in the lung of the developing rabbit fetus and newborn. Pediatr. Res.. 1: 247 $(1967)$.

15. Havden, W. Ohson, L. B.. and Zachman, R. D.: Lllect of matemal soxuprenc on fetal rabhit lung biochemical maturation. Am. J. Obstet. (ivnecol.. 124: 691 (1977)

16. Kero. P.. Hirvonen. T.. and Valimaki. I.: Prenatal and postnatal isoxuprine and respiratory distress syndrome. Iancet, 2: 198 (1973).

17. Kikkawa. Y.. Motoyama. E. K.. and (iluck. L.: Study of the lungs of fetal and newborn rabbits. Morphologic, biochemical and surface physical development. Am. J. Pathol. 52: 177 (1968).

18. Kotas. R. V.. and Avery. M. E.: Accelerated appearance of pulmonary surfactant in the fetal rabbit. J. Appl. Physiol., 30: 358 (1971).

19. Lagercrant\%. H., and Bistoletti. P.: (atecholamine release in the newborn infant at birth. Pediatr. Res.. 11: $8 \times 9$ (1977).

20. Lands, A. M., Arnold, A.. McAuliff. J. P.. Luduena. F. P.. and Brown. T. G.. Jr.: Differentiation of receptor systems activated by sympathomimetic amines. Nature (Lond.), 214: 597 (1967).

21. Olver. R. E... and Strang. 1.. B.: Ion liuxes across the pulmonary epitheltum and the secretion of lung liquid in the fetal lamb. J. Physol (Lond.), 241: 327 (1974) 
22. Pappano. A. J.: Ontogenetc development of atutonoms neuroeffector transmision and transmiter reactivity in embryonic and fetal hearts. Pharmacol. Rev. 2.: $3(1077)$

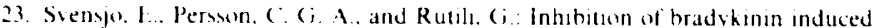
macromolecular leakage from post-capillarv venules by a B.-adrenoreceptor stumulant. terhutaline Acta Physiol. Scand. 101): $5(14$ (1977).

24. Waliers, D. V.. and Olver. R. I. The role of catecholamines in lung liquid abourptoon at birth. Pediatr. Res. 12: 239 (1978)

25. Whangrodskı. I. Taeusch. H. W.. and Avery. M. F.. Isoxuprine-induced alteratons of pulmonary pressure-solume relationship in premature rabbits. Am.

(opyright 1980 ) International Pediatric Research Foundation. Inc (k) $3 i-394 \% / 80 / 14199-1067 \$ 02.00) / 0$
J. Ohatet. (iynecol.. /19: 1107 (1974).

26. The lechnical issistance hy Lena Nystrom. Britt-Marie Otterstedt. and Gabriella Salen is gratefully acknowledged

27. Reyuests for reprints should be addressed to: Boinge Bergman, M.D. Kuinnokliniken. (entrallasarettet. $\$-43$ ! 80 Molndal. Sweden

28. This research was supported by grants from the Swedish Medical Research Council (no. 2462), the Medical Faculty. University of (joteborg. and "(jitehorgs Lakaresallskap."

29. Received for publication September 6. 1979

30. Accepted for publication January 2. 1980. 